\title{
Alemtuzumab for multiple sclerosis: the new concept of immunomodulation
}

\author{
Paolo Gallo ${ }^{1^{*}}$, Diego Centonze ${ }^{2}$ and Maria Giovanna Marrosu ${ }^{3}$
}

\begin{abstract}
Alemtuzumab (Lemtrada ${ }^{\oplus}$ ) is a humanized anti-CD52 lgG1 monoclonal antibody that depletes CD52-expressing cells from the circulation. Robust clinical and radiologic data, derived from clinical trials and long-term observational studies, indicate that alemtuzumab induces a marked immunosuppression related to the depletion of circulating $T$ and B lymphocytes. However, recent advances suggest that the long-term clinical effects of alemtuzumab are probably due to unique qualitative changes in the process of lymphocyte repopulation of the immune system. This leads to a particular rebalancing of the immune system. In this paper we review the immunomodulatory mechanisms underlying the therapeutic effect of alemtuzumab in pre-clinical models and in patients with relapsing remitting multiple sclerosis (RRMS), and stress the importance of a monoclonal antibody-based immunosuppression for treating the severe forms of RRMS. Alemtuzumab has many features of the ideal immunomodulatory drug: rapid biological and clinical actions and and long-lasting benefit. Alemtuzumab can be used as rescue therapy or as first line drug in severe-onset MS. Thus, the availability of alemtuzumab constitutes a significant step forward in the therapy of MS.
\end{abstract}

Keywords: Alemtuzumab, Multiple sclerosis, Immunomodulation

\section{Background}

Alemtuzumab, previously known as Campath- $1 \mathrm{H}$, is a recombinant, humanised, monoclonal immunoglobulin IgG1 kappa, that targets the cell-surface glycoprotein CD52 $[22,23]$. Alemtuzumab induces antibody-dependent cellular cytotoxicity (ADCC) and complement-dependent cytotoxicity (CDC), and activates pro-apoptotic pathways on CD52-expressing cells. One phase-2 trial (CAMMS-223) and two phase-3 studies (CARE-MS1 and CARE-MS2) have clearly demonstrated the efficacy of alemtuzumab in the treatment of naive patients and have established its superiority over high-dose high-frequency interferon beta-1a (IFNb-1a) in patients who continue to experience relapses despite of first-line therapy [9-11]. Alemtuzumab primary safety concern is the development of secondary autoimmunity, that occurs up to five years after the first cycle of infusions and peaks at two years. Indeed, about $30 \%$ of patients develop thyroid autoimmunity and 1\% idiopathic thrombocytopenic purpura (ITP). In addition, 4 out of

\footnotetext{
* Correspondence: paolo.gallo@unipd.it

${ }^{1}$ Department of Neuroscience DNS, Multiple Sclerosis Centre, University

Hospital, Via Giustiniani, 5, 35129 Padova, Italy

Full list of author information is available at the end of the article
}

1486 patients $(<0.3 \%)$ enrolled in phase II and II trials developed autoimmune glomerulonephritis.

In September 2013, the European Medicine Agency (EMA) approved alemtuzumab as a first-line therapy for adults with active relapsing remitting multiple sclerosis, under the trade name Lemtrada. Lemtrada is now also approved as a treatment of multiple sclerosis in US, Canada, Australia, Switzerland, Israel, and many countries in South America. This review focuses on the mechanisms of action of alemtuzumab on the immune system (Table 1) and tries to explain the long lasting biological and clinical effects of this monoclonal antibody on multiple sclerosis (MS).

\section{CD52, the target}

CD52 is a short peptide of 12 amino acids highly expressed on $\mathrm{T}$ and $\mathrm{B}$ lymphocytes, and at very low levels on natural killer cells, monocytes and macrophages (Fig. 1), while neutrophils, dentritic cells and bone marrow stem cells don't express this molecule (Buggings et al., 2002). Further, CD52 is found within the male genital tract and is present on the surface of mature sperm cells. Since it is highly negatively charged it has been supposed that its 
Table 1 Biological effects of Alemtuzumab

\begin{tabular}{|c|c|c|}
\hline Effects & Mechanisms & References \\
\hline $\begin{array}{l}\text { Fast and long-lasting immune } \\
\text { suppression }\end{array}$ & $\begin{array}{l}\text { Rapid and complete depletion of circulating T and } \\
\text { B lymphocytes; limited effect on lymphoid organs. } \\
\text { Differentiated CD20, CD4 and CD8 lymphocyte } \\
\text { repopulation (B before T, T4 before T8) } \\
\text { Long-lasting re-modelling of the lymphocyte } \\
\text { network: earlier appearance of regulatory B and T } \\
\text { cells, later appearance of Th1 and Th17. } \\
\text { Anti-inflammatory changes in the cytochine network. } \\
\text { More tolerogenic immune network during reconstitution. }\end{array}$ & $\begin{array}{l}\text { Hu et al., } 2009 \text { [29] } \\
\text { Thompson et al., 2010 [38] } \\
\text { Jones et al., } 2009 \text { [30] } \\
\text { Zhang et al., } 2013 \text { [42] } \\
\text { Turner et al., } 2013 \text { [40] } \\
\text { Havari et al., } 2015 \text { [25] } \\
\text { Wang et al., } 2015 \text { [43] } \\
\text { Wang et al., } 2015 \text { [43] } \\
\text { Watanabe et al., } 2006 \text { [44] }\end{array}$ \\
\hline $\begin{array}{l}\text { Decrease in brain inflammation } \\
\text { and neurodegeneration }\end{array}$ & $\begin{array}{l}\text { Almost complete suppression of brain inflammation. } \\
\text { Increased production of neurotrophic/growth factors by } \\
\text { antigen-specific T cells. }\end{array}$ & $\begin{array}{l}\text { Jones et al., } 2010 \text { [31] } \\
\text { Turner et al., } 2015 \text { [41] }\end{array}$ \\
\hline No impact on immune competence & $\begin{array}{l}\text { Immunocompetent cells in the lymphoid organs } \\
\text { are largely preserved. } \\
\mathrm{B} \text { and T cell response against bacterial and viral } \\
\text { antigens are maintained during therapy. } \\
\text { Innate immunity is not affected. }\end{array}$ & $\begin{array}{l}\text { Hu et al., } 2009 \text { [29] } \\
\text { Buggins et al., } 2002[6] \\
\text { McCarthy et al., } 2013 \text { [34] } \\
\text { Clark et al., } 2012 \text { [7] } \\
\text { Turner et al., } 2013 \text { [40] }\end{array}$ \\
\hline Cytokine release syndrome & $\begin{array}{l}\text { Transient, cytolysis-related release of pro- } \\
\text { inflammatory acute-phase cytokines (TNF, IL-1, IL-6). }\end{array}$ & $\begin{array}{l}\text { Breslin et al., } 2007 \text { [4] } \\
\text { Wing et al., } 1996 \text { [45] } \\
\text { Bugelski et al., } 2009 \text { [5] }\end{array}$ \\
\hline
\end{tabular}

function consisted in hampering cell adhesion, thus allowing cells to freely move around (see the review of [23]). Although a recent study has found that activated CD4 $\mathrm{T}$ cells expressing high levels of CD52 may have regulatory activities on $\mathrm{T}$ effector lymphocytes [2] the function of CD52 remains partially unknown.

Human and mouse antigen-activated $\mathrm{T}$ cells with high CD52 expression were demonstrated to suppress other $\mathrm{T}$ cells. CD $4+\mathrm{CD} 25+\mathrm{CD} 52^{\text {high }} \mathrm{T}$ cells are distinct from $\mathrm{CD} 4+\mathrm{CD} 25^{\text {high }}$ Foxp3 + regulatory $\mathrm{T}$ cells inasmuch as they suppress auto-reactive $\mathrm{T}$ cell subsets by releasing soluble CD52 (CD52s). CD52s binds to the inhibitory receptor sialic acid-binding immunoglobulin-like lectins-
10 (Siglec-10) thus impairing the phosphorylation of the $\mathrm{T}$ cell receptor (TCR)-associated kinases Lck and Zap70 (Fig. 2). The final result is a down regulation of TCR assembly and, consequently, $\mathrm{T}$ cell activation. Humans with autoimmune diabetes were found to have a lower frequency and diminished function of CD4 + CD25 + CD52 ${ }^{\text {high }} \mathrm{T}$ cells responsive to the autoantigen GAD65. In diabetes-prone mice of the non-obese diabetic (NOD) strain, transfer of lymphocyte populations depleted of $\mathrm{CD} 4+\mathrm{CD} 25+\mathrm{CD} 52^{\text {high }}$ cells results in a more severe disease [2].

Beside the CD52-Siglec-10 ligand-receptor mechanism, the CD52 molecule may down-regulate $\mathrm{T}$ cell activation

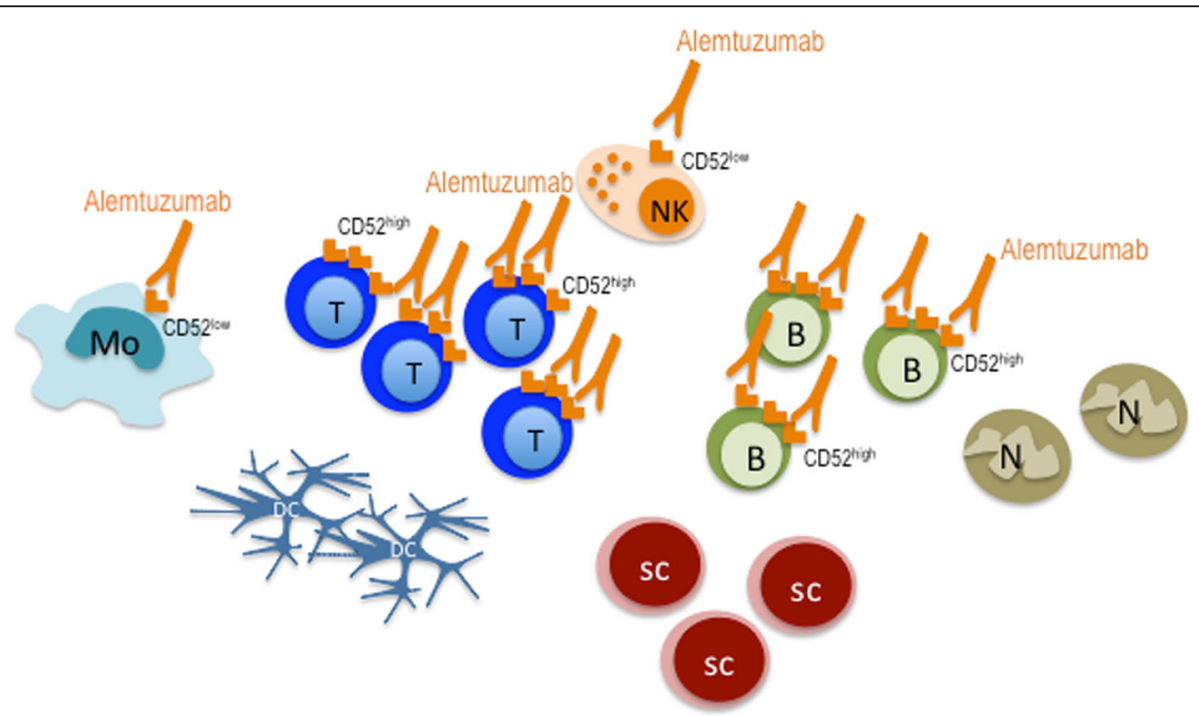

Fig. 1 CD52 is a short peptide of 12 amino acids highly expressed on T and B lymphocytes, and at very low levels on natural killer cells (NK), monocytes and macrophages (Mo), while neutrophils (N), dendritic cells (DC) and bone marrow stem cells (SC) do not express this molecule 


\section{T \& B lymphocytes}

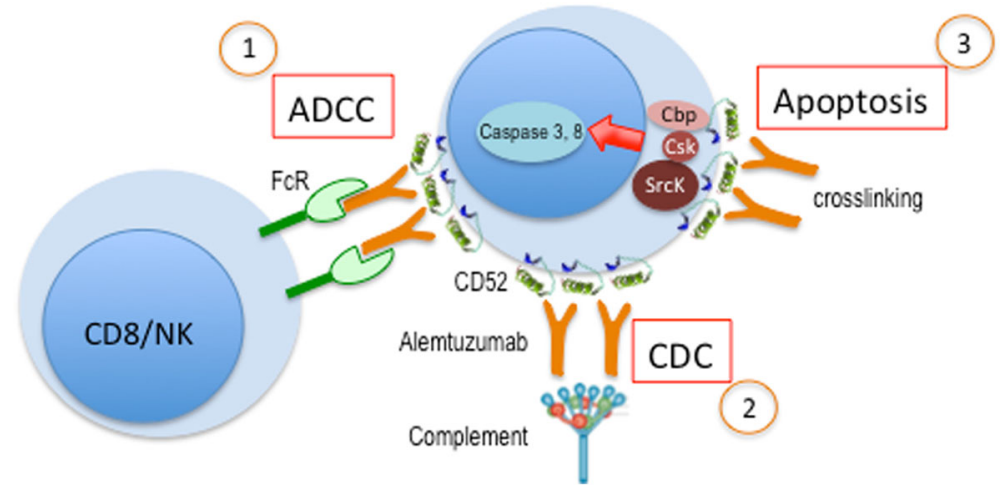

Fig. 2 On T and B cells expressing high concentrations of CD52, alemtuzumab (lgG1 k) activates: 1) antibody-dependent cell-mediated (CD8 and $\mathrm{NK})$ cytotoxicity (ADCC), 2) complement-dependent cytotoxicity (CDC), 3) caspase-dependent apoptosis

by molecular cross-linkage mediated by an as yet unidentified endogenous ligand that, in vitro, might be mimicked by a bivalent anti-CD52 antibody [3]. These two (cytolitic and pro-apoptotic) mechanisms may operate in a synergistic manner.

Since one third of alemtuzumab-treated patients develop autoimmune diseases, in particular autoimmune thyroiditis [17, 18], it might be possible that the longlasting deletion of $\mathrm{CD} 4+\mathrm{CD} 25+\mathrm{CD} 52^{\text {high }} \mathrm{T}$ cells following therapy needs may account for these adverse events.

However, the impairment of the CD $4+\mathrm{CD} 25+$ CD52 ${ }^{\text {high }}$-mediated T-cell regulation following alemtuzumab administration does not constitute a concern with regard of MS since alemtuzumab exerts a strong immunosuppressive activity by activating (see below) the ACDC and CDC mediated lysis of $\mathrm{T}$ and $\mathrm{B}$ lymphocytes and inducing caspase-dependent cell apoptosis, leading to a marked global lymphocyte depletion that includes autoreactive pathogenic lymphocytes. The density of CD52 on cell surface is believed to influence the susceptibility of lymphoid cells to alemtuzumab-induced ACDC and CDC [37], but other factors, e.g. the level of expression of complement-inhibitory proteins, were also suggested to play a role especially in protecting cell lysis in the lymphoid organs [Genzyme, EU summary of product characteristics, 2013; [36] (Fig. 3).

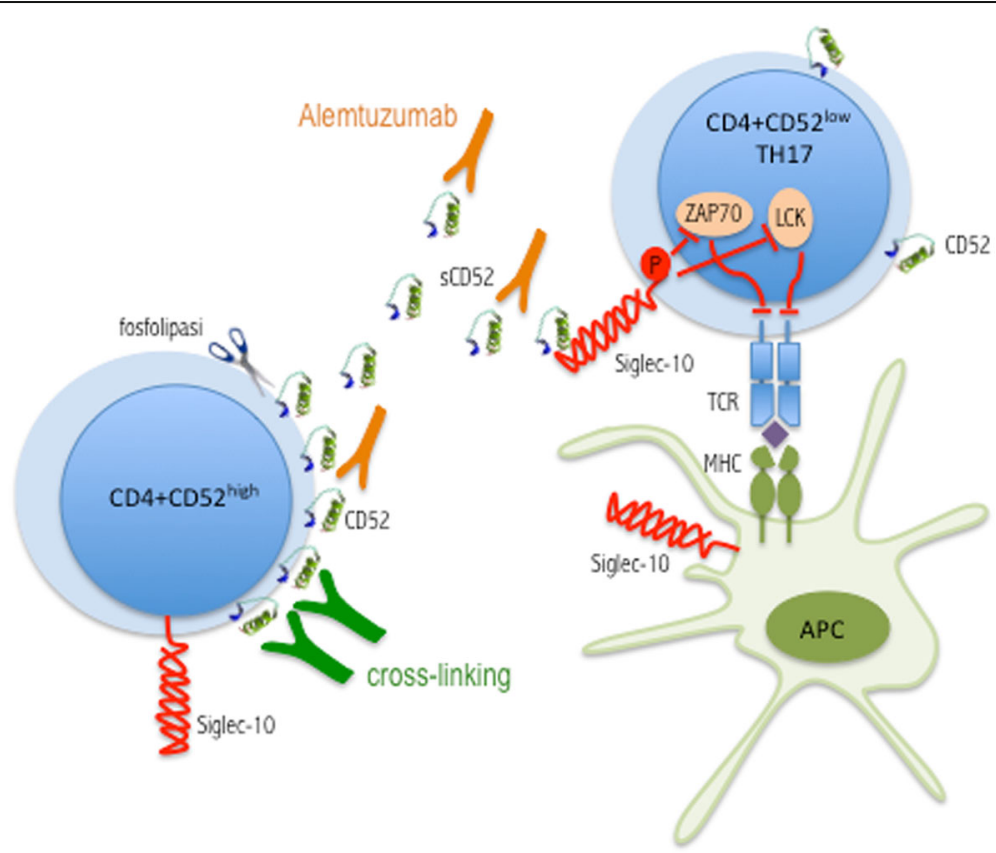

Fig. $3 \mathrm{~T}$ cell regulation mediated by interaction of soluble CD52 with the inhibitory receptor Siglec-10 


\section{Pre-clinical studies}

\section{Transgenic hu-CD52 mice}

Since alemtuzumab does not cross-react with mouse CD52, a transgenic mouse model expressing the human CD52 molecule (huCD52) was created to assess, in preclinical experimental/animal settings, the effects of alemtuzumab on lymphocyte subsets in lymphoid organs [29]. The administration of a single $10 \mathrm{mg} / \mathrm{kg}$ dose of alemtuzumab to huCD52-transgenic mice replicated the depletion of $\mathrm{B}$ and $\mathrm{T}$ lymphocyte circulating populations observed in human studies, with little effect on cells of the innate immune system (neutrophils and NK cells). Lymphocyte depletion in lymphoid organs (spleen, thymus, lymph nodes) was less profound than in the blood and was mediated primarily through ADCC exerted by neutrophils and NK cells, and largely independent of CDC [29]. At higher alemtuzumab doses, the degree of lymphopenia in the lymphoid organs (especially in spleen and lymph nodes) was definitely less profound compared to that observed in the peripheral circulation. This can be explained by the fact that, at the therapeutic dosage, alemtuzumab is largely absorbed by circulating lymphocytes, thus making its penetration in the lymphoid organs very limited. Moreover, it might be possible that the effector mechanisms responsible for cell depletion are less abundant or effective in lymphoid organs compared with peripheral blood. Interestingly, a relative sparing of $\mathrm{T}$ cells with a regulatory phenotype (CD4 + CD25 ${ }^{\text {high }}$ FoxP3+) compared to total CD4+ T cell population was observed in both the blood and spleen even though both populations express equivalent levels of CD52 on their surface. The mechanism and significance of this apparent sparing of $\mathrm{T}$ cells with a regulatory phenotype remain unclear but could be a relevant factor in determining the long term suppression of inflammation obtained by alemtuzumab therapy.

In hu52 mice, lymphocyte repopulation was also very similar to that observed in humans. Namely, B lymphocytes returned to baseline levels by 7-10 weeks posttreatment while $\mathrm{CD} 4+$ and $\mathrm{CD} 8+\mathrm{T}$ cells recovered more slowly and were still below the baseline levels at weeks 25. One possible explanation for the differential timing of $\mathrm{T}$ and $\mathrm{B}$ cell repopulation in the blood might be that alemtuzumab did not significantly affect the bone marrow thus allowing for the rapid recovery of $B$ lymphocytes, while the effect on thymus determined a partial depletion of thymocytes, which could account, at least partly, for the slower recovery of $\mathrm{T}$ lymphocytes. Indeed, examination of the thymus of the transgenic mouse disclosed a partial depletion of single-positive and double-positive thymocytes (reaching $50 \%$ at the dose of $10 \mathrm{mg} / \mathrm{kg}$ of alemtuzumab). However, while the partial loss of thymocytes may, at least partly, explain the delay in T-cell recovery, the explanation for the long-lasting duration of T-cell lymphopenia is still missing.

In the huCD52-transgenic mice it was also possible to replicate the transient increase in serum cytokine levels observed in humans, and responsible for the so-called 'cytokine released syndrome' and mainly related to the acute liberation of pro-inflammatory cytokines, such as TNFalpha, IL-1 beta, IL-6.

The functional properties of immune cells that remained following alemtuzumab treatment in huCD52 mice were also evaluated [29]. T lymphocytes showed in vitro proliferation rates and cytokine production in response to anti-CD3 Mab stimulation very similar to that observed in vehicle-treated mice. The T-cell receptor repertoire and the efficiency of $\mathrm{T}$-cell response against a viral challenge were also maintained after alemtuzumab treatment. The primary $\mathrm{T}$-cell response against viruses was explored by challenging the huCD52 transgenic mice with the adenovirus vector $\operatorname{Ad} 2$ at 7,21 , or 35 days after alemtuzumab treatment. T-cell responses were reduced at 7 and 21 days post alemtuzumab treatment, but comparable to that observed in control animals after five weeks later, before T-cell counts returned to pre-treatment levels. The primary B-cell response was also modestly affected. The antibody response to a $\mathrm{T}$ dependent antigen was attenuated 3 days after alemtuzumab treatment (the nadir of lymphocyte depletion), but was similar to vehicle-treated controls at 21 days [29]. Preserved immune responses in alemtuzumab-treated animals may be due, in part, to the activity of residual $B$ and $\mathrm{T}$ lymphocytes within peripheral lymphoid organs.

These observations were further confirmed in a study aimed at evaluating the impact of alemtuzumab treatment on number and function of innate immune cells in the same murine [40]. Following alemtuzumab administration, a transient decrease in primary adaptive immune responses was observed, but there was little effect on memory responses. Namely, the antibody response to a T-independent antigen was not significantly affected by the treatment suggesting that the remaining B lymphocytes were still capable to mount a normal antibody response. On the contrary, the antibody response to a Tdependent antigen was impaired when immunization was performed few days after alemtuzumab treatment, but returned to control levels by day 21 post-therapy. A mild, transient decline on primary $\mathrm{T}$ cell responses was also observed in mice immunized with adenovirus Ad2, but the difference with not treated mice did not reach statistical significance. Interestingly, $\mathrm{T}$ cell response to Ad2 returned to control levels by despite peripheral $\mathrm{T}$ lymphocyte counts were still suppressed.

Data in hu-CD52 transgenic mice and in experimental autoimmune encephalomyelitis (EAE) suggest that the effect of alemtuzumab on the immune network is 
multifaceted, and probably includes a disequilibrium in the lymphocyte numbers, alterations in the functional properties of some lymphocyte subsets, and a transient effects on components of innate immunity. Particular intriguing is the observation that, after alemtuzumab treatment, naive $\mathrm{CD} 4+$ and $\mathrm{CD} 8+\mathrm{T}$ cells in the spleen were the most susceptible to depletion, whereas central and effector memory $\mathrm{T}$ cells, as well as Tregs, were depleted to a lesser extent, despite equivalent levels of CD52 expression on their surfaces.

All together, the observations done in $\mathrm{Hu}-\mathrm{CD} 52$ transgenic mice suggest that protective levels of $\mathrm{T}$ cell immunity against infection can still be present despite the marked $\mathrm{T}$ and $\mathrm{B}$ cell lymphopenia. Animal data agree with the clinical data in humans showing that the highest risk of infection occurs in the first month postalemtuzumab treatment and declines thereafter even though blood $\mathrm{T}$ cell counts remain below the normal range [12]. This may be partly explained by the recovery of sufficient numbers of lymphocytes in the lymphoid organs that can participate in the development of immune responses.

\section{Experimental autoimmune encephalomyelitis}

The effect of anti-CD52 therapy was tested in three murine models of the brain autoimmune inflammation, the EAE, that reproduces some of the histological features of MS: EAE induced by MOG35-55 (myelin oligodendrocyte glycoprotein) in C57BL/6 mice, which represents a standard acute model of disease primarily driven by peptide-specific CD4+ lymphocytes; chronic EAE induced by MOG1-121, that is believed to involve the contribution of both $\mathrm{T}$ and $\mathrm{B}$ lymphocytes in the pathogenesis; and relapsing remitting EAE induced by PLP139-151 (proteolipid protein) in SJL mice [40]. Treatment with a single course of anti-muCD52 in mice with early symptoms (day 12-16 from immunization) achieved long term control of disease in all 3 models demonstrating efficacy against the different aspects of disease pathogenesis. In the $\mathrm{MOG}_{35-55}$ model, the delayed administration of anti-muCD52 at the time the mice attained more significant disability, with a disease score of 2 that corresponds to a full tail paralysis and hind limb paresis, was still efficacious and resulted in the almost complete reversal of disease symptoms. Interestingly, the control of disease was maintained up to $\sim$ day 90 without further retreatment in spite of complete lymphocyte repopulation in the blood and lymphoid organs.

Histological examination disclosed a significant reduction of immune cell infiltration in all regions of the spinal cord in anti-muCD52-treated mice vs control mice. This was accompanied by a significant reduction in the degree of spinal cord demyelination and axonal damage. Administration of anti-muCD52 not only reduces the number of circulating $\mathrm{T}$ lymphocytes, but also reduces the number of infiltrating $\mathrm{T}$ lymphocytes in the CNS of EAE mice, decreases the number of MOGreactive $\mathrm{CD} 4 \mathrm{~T}$ cells and overall cytokine production and strongly inhibited the development of CNS inflammation and concomitant demyelination and axonal damage. Electrophysiological assessment showed preservation of axonal conductance in the spinal cord suggesting that anti-CD52 therapy may help to preserve CNS integrity [41]. Taken all together, these results demonstrate the robust general and local immunosuppressive action of anti-muCD52 treatment in several models of EAE and parallel the long term control of disease observed in the majority of RRMS patients treated with alemtuzumab.

Thus, experimental studies in vitro and in animal models have 1) confirmed the mechanism of action of alemtuzumab, 2) reproduced the kinetics of lymphocyte depletion and repopulation observed in humans and 3) correlated the strong, rapid and long-lasting immunosuppression to a significant reversion/amelioration of autoimmune-mediated brain inflammation.

\section{Studies in humans}

Alemtuzumab-treated patients exhibited a nearly complete depletion of circulating CD4(+) lymphocytes within few hours after administration with a nadir between day 3 and 7. The reconstitution of the circulating lymphocyte repertoire was found to follow peculiar kinetics. In the CAREMS-I and -II studies, alemtuzumab was associated with a decrease in circulating lymphocyte counts after each treatment course, but had few or transient effects on other leukocytes (neutrophils, monocytes, eosinophils, basophils and natural killer cells) $[8,11,12]$. The total lymphocyte count returned to the lower limit of the normal values by month 6 in about $40 \%$ of patients and by month 12 in about $80 \%$ of patients. In one study, however, CD4+ lymphocytes remained significantly decreased for up to 24 months [42], while in another study both CD4+ and CD8+ lymphocyte counts remained below baseline levels for a median of 61 and 30 months, respectively [13]. B cell numbers returned to baseline by 3 months, and in some cases their number increased beyond baseline levels at 27 months (but rarely exceeded the upper limit of normal values) $[13,19]$.

In a follow-up study in 36 MS patients (384 person years), aimed at analysing the long term effects of a single course of alemtuzumab (100 mg over 5 infusion days, a dose higher than that currently use in MS) on lymphocyte reconstitution, the geometric mean recovery time of total lymphocyte counts to the lower limit of the normal range $\left(\geq 1.0 \times 10^{9}\right.$ cells $\left./ \mathrm{L}\right)$ was 12.7 months. For B cells the recovery time was 7.1 months, while CD8+ and CD4+ lymphocytes returned within the normal ranges in 
20 and 35 months, respectively, but only in a minority of the patients they returned within the baseline values (30\% and $21 \%$, respectively). In spite of prolonged lymphocyte depletion, no infective safety concerns were observed [28].

The lymphocyte reconstitution profile that follows alemtuzumab-induced lymphocyte depletion appear very similar to that observed after marked immunosuppression obtained with other therapies, for instance haematopoietic stem cell transplantation, and suggests that it might be driven by common homeostatic mechanisms, such as proliferation of mature lymphocytes that escaped depletion, or by ex-novo lymphocyte production from precursors in the thymus $[19,32]$.

During the reconstitution phase of the circulating lymphocyte repertoire, CD4(+)CD25(+)CD127(low) regulatory $\mathrm{T}$ cells preferentially expanded within the CD4(+) lymphocyte population, reaching peak expansion at month 1 . The increase in the percentage of TGF- $\beta 1$, IL10 , and IL-4 producing CD4(+) cells (Th2 phenotype) reached the higher level at month 3 , whereas Th1 and Th17 Th cells increased much slowly and returned within the normal values at months 12 . However, a significant decrease in the percentages of Th1 and Th17 cells was still detected at months 12 and 24 in comparison with the baseline values. A gradual increase in serum IL-7 and IL-4 and a decrease in IL-17A, IL-17 F, IL-21, IL-22, and IFN- $\gamma$ levels were also demonstrated following treatment. These observations are in line with in vitro studies that disclosed that IL-7 induced an expansion of $\mathrm{CD} 4(+) \mathrm{CD} 25(+) \mathrm{CD} 127$ (low) regulatory $\mathrm{T}$ cells and a decrease in the percentages of Th17 and Th1 cells, and further indicates that the differential reconstitution of $\mathrm{T}$ cell subsets and selectively delayed CD4(+) $\mathrm{T}$ cell repopulation following alemtuzumab-induced lymphopenia may partly contribute to its long-lasting suppression of disease activity [42] (Fig. 4).
In a recent 24-month multicentre study aimed at evaluating Th and Treg repopulation and function during alemtuzumab therapy in 29 MS patients, CD4+ cell percentage remained significantly lower compared to baseline, while a significant increase in Treg percentage was observed at month 24 and was accompanied by an increase in Treg suppressive activity against myelin basic protein-specific Th1 and Th17 cells [20]. Although the meaning of the increase in percentage and function of Treg in the late phase of alemtuzumab therapy is unclear and need to be investigated in larger numbers of patients, these findings further suggest that CD52 depletion induces a transient re-arrangement of the $\mathrm{T}$ cell network.

With regard to the analysis of lymphocyte subsets, data coming from CARE-MS-I and II showed that the relative proportion of $\mathrm{CD} 4+$ naive $\mathrm{T}$ cells decreased (from 36 to 5\% [CARE-MS-I] and from 37 to $2 \%$ [CARE-MS-II]) and the relative proportion of CD4+ memory $\mathrm{T}$ cells increased (from 63 to $94 \%$ and from 63 to $97 \%$, respectively) by month 1 and returned to nearbaseline levels by month 12 , while the relative proportions of $\mathrm{CD} 4+\mathrm{CD} 25+$ regulatory $\mathrm{T}$ cells increased by month 1 (from 3 to $14 \%$ and from 4 to $13 \%$, respectively) and remained elevated at month 12 [24]. A similar pattern was observed for $\mathrm{CD} 8+\mathrm{T}$ cells. Moreover, the relative proportion of mature nave $B$ cells decreased and the relative proportion of immature B cells increased by month 1 and approached baseline levels by month 6 . It has been suggested that early $\mathrm{T}$-cell reconstitution occurs via the expansion of existing cells which have escaped depletion, rather than via generation of new $\mathrm{T}$ cells in the thymus [32]. This may, at least partly, contribute to the development of secondary autoimmunity following alemtuzumab treatment, as peripheral expansion favours immune populations that respond to selfantigens [32]. However, as above mentioned, human and

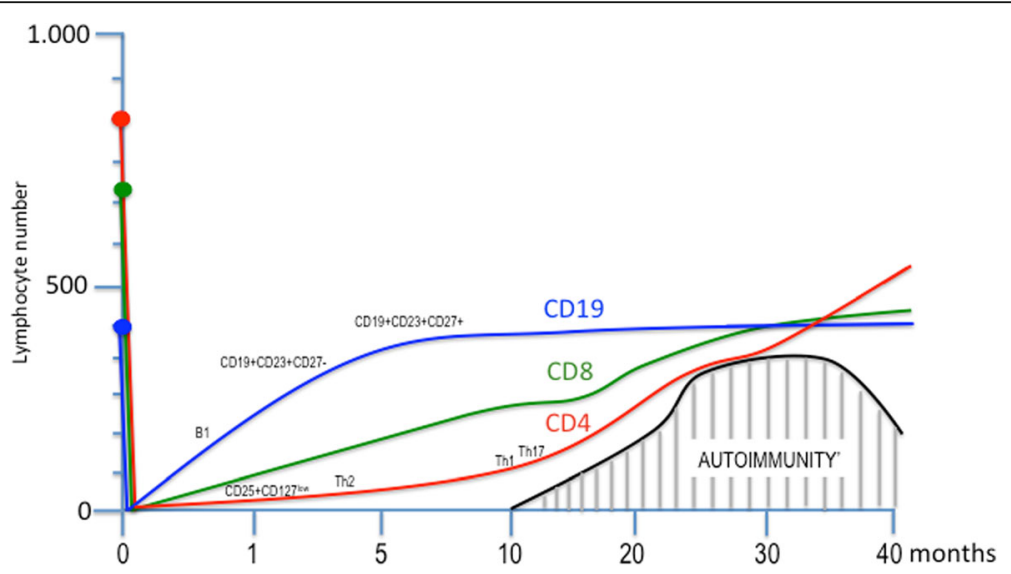

Fig. 4 Time-course repopulation of lymphocyte subpopulations in alemtuzumab-treated multiple sclerosis patients 
mouse antigen-activated $\mathrm{CD} 4+\mathrm{T}$ cells with high expression of CD52 on their surface $\left(\mathrm{CD} 4+\mathrm{CD} 52^{\text {high }}\right)$ were demonstrated to exert a suppressive action on other $\mathrm{T}$ cells by releasing CD52s. The demonstration that humans with autoimmune diabetes have a lower frequency and diminished function of $\mathrm{CD} 522^{\text {hi }} \mathrm{CD} 4+\mathrm{T}$ cells responsive to the autoantigen GAD65 is particularly worth of interest, since it suggests a role of this $\mathrm{T}$ cell subpopulation in human autoimmunity. While these findings identify a CD52-mediated $\mathrm{T}$ cell regulatory mechanism that may protect from autoimmune diseases, they suggest that the impairment of this mechanism may contribute, at least partly, to the appearance of autoimmune disorders in alemtuzumab-treated individuals [2].

Alemtuzumab administration is associated with the acute induction of several pro-inflammatory cytokines, such as tumour necrosis factor-alpha (TNFa), interleukin6 (IL-6) and interferon gamma (IFNg). This is due to the cross-linking of natural killer cells and to the lysis of lymphocytes and cells of the monocyte/macrophage lineage with subsequent release of pro-inflammatory cytokines that peaks 2-6 $\mathrm{h}$ after infusions and causes the so-called "cytokine-release syndrome).

However, the long-lasting effect of alemtuzumab on the cytokine network consists in the down-regulation of pro-inflammatory interleukins that may also be considered a major mechanism underlying the therapeutic effect of the drug. Indeed, in a study investigating cytokine production by ex vivo stimulated T cells obtained from MS patients treated for 12 months with alemtuzumab a long-lasting decrease in the secretion of IL-17 and IL-22 (produced by Th17 cells) was observed [27].

The immune-competence following alemtuzumab therapy was assessed in a pilot case-control study involving 24 patients [34]. The antibody responses to 3 vaccines (1. diphtheria, tetanus, and poliomyelitis vaccine, 2. Haemophilus influenzae type $\mathrm{b}$ and meningococcal group $\mathrm{C}$ conjugate vaccine, and 3 . pneumococcal polysaccharide vaccine). The antibody titres against common viruses (mumps, rubella, varicella-zoster, and EpsteinBarr virus) were measured before alemtuzumab treatment and 1 and 9-11 months after treatment. Serum antibodies against common viruses remained detectable after treatment, and vaccine responses were normal to T-cell-dependent recall antigens (tetanus, diphtheria, and polio), to T-cell-dependent novel antigen (meningococcus $\mathrm{C}$ ), and to T-cell-independent antigens (pneumococcal). No evidence for a diminished response to vaccinations in 5 patients studied within 6 months of alemtuzumab treatment was observed. Thus, alemtuzumab treated individuals retain 1) humoral immunologic memory (in the form of antibodies against common viruses and response to recall antigens), and 2) the ability to mount a humoral immune response against a novel antigen. These data indicate that patients with relapsing remitting multiple sclerosis appear immunocompetent after treatment with alemtuzumab.

Alemtuzumab treatment was found to significantly reduce the risk of relapse and accumulation of disability compared with high-dose, high-frequency interferon beta 1a. The post hoc subgroup analyses of the CAMMS223 trial disclosed that among patients with no clinical disease activity immediately before treatment, or any clinical or radiological disease activity on-trial, disability improved after alemtuzumab but not following interferon beta. These observations led to the hypothesis that disability improvement after alemtuzumab was not only the result of the antiinflammatory activity of the drug, but could in part be due to a sort of 'protective' effect mediated by neurotrophic factors possibly produced by lymphocytes. Indeed, after alemtuzumab, and only when specifically stimulated with myelin basic protein, peripheral blood mononuclear cell (PBMC) cultures produced increased concentrations of brain-derived neurotrophic factor, platelet-derived growth factor and ciliary neurotrophic factor [31]. Analysis by reverse transcriptase polymerase chain reaction of cell separations showed that the increased production of ciliary neurotrophic factor and brain-derived neurotrophic factor after alemtuzumab was attributable to increased production by $\mathrm{T}$ lymphocytes. Media from these postalemtuzumab PBMC cultures promoted survival of rat neurones and increased axonal length in vitro, effects that were partially reversed by neutralizing antibodies against brain-derived nerve growth factor and ciliary neurotrophic factor. This conditioned media also enhanced oligodendrocyte precursor cell survival, maturation and myelination. The hypothesis that alemtuzumab-induced lymphocyte-derived neurotrophins mat play a neuro-protective role in vivo in MS patients needs further investigations.

\section{Pharmacokinetic data}

The pharmacokinetics of alemtuzumab were investigated in a study involving 216 patients with RRMS who received a first treatment course of intravenous infusions of alemtuzumab 12 or $24 \mathrm{mg} /$ day on 5 consecutive days, followed by a second course with the same dosage on 3 consecutive days one year later. The highest serum concentration of alemtuzumab was observed following the last infusion of each treatment course; serum concentration increased with each consecutive dose within the course. The mean maximum serum concentration (Cmax) was $3014 \mathrm{ng} / \mathrm{mL}$ on day five of the initial treatment course, in recipients of alemtuzumab $12 \mathrm{mg}$; the mean Cmax was 2,276 ng/ $\mathrm{mL}$ on day three of the second treatment course. 
Classical biotransformation studies have not been conducted for alemtuzumab, as yet. The alpha elimination half-life was \& 4-5 days in both treatment courses, and low or undetectable serum concentrations occurred within \& 30 days of the end of each treatment course. No sufficient data are available to draw conclusion on the effect of race or sex on alemtuzumab pharmacokinetics and no formal drug interaction studies have been conducted for alemtuzumab at the recommended dosage in patients with MS (Genzyme Therapeutics Ltd. LemtradaTM, EU summary of productcharacteristics. 2013. [21] http:// www.ema.europa.eu/docs).

\section{Clinical trials and extension data}

The effects of alemtuzumab on clinical and magnetic resonance parameters in patients with active RRMS have been investigated in one Phase II (Campath-1H in Multiple Sclerosis, CAMMS223) and two Phase III (Comparison of Alemtuzumab and Rebif efficacy in Multiple Sclerosis, CARE-MS-I and CARE-MS-II) randomized, rater-blinded, active comparator-controlled, multinational trials. Five years extension data have been made recently available from all these studies $([8,10-12]$, Coles et al., 2013).

In CAMMS223 (enrolment period: December 2002July 2004), 334 treatment nave RRMS patients with a disease duration $<3$ years were randomized to receive 1 ) treatment with i.v. infusion of alemtuzumab $12(n=113)$ or $24(n=110) \mathrm{mg} /$ day on 5 consecutive days, followed by a second treatment course at the same dosage on 3 consecutive days at months 12 and 24, or 2) subcutaneous interferon beta-1a $44 \mathrm{mcg}$ tiw $(n=111)$. On September 2005, the trial was suspended for the appearance of three cases (one death) of alemtuzumabrelated immune thrombocytopenic purpura (ITP). Interferon beta-1a treatment continued as planned. In 2008, the dosing suspension was lifted, an option redosing was given to the patients and a safety monitoring programme (ended in January 2010) was planned and carried on. Compared to IFNb-1a, alemtuzumab $12 \mathrm{mg} /$ day was significantly more effective in reducing the relapse rate $(-67 \% p<0.0001)$, in increasing the number of relapse-free patients $(76 \%$ vs. $50 \%, p<0.0001)$ and in decreasing the sustained accumulation of disability (SAD) ( $8 \%$ vs. $27 \%, p=0.0006$ ). The MRI finding were also impressive: compared to IFNb, alemtuzumab-treated patients had a lower increase in T2WM lesion volume $(p=0.005)$ and a lower reduction in brain volume on T1 images $(p=0.05)$.

In CARE-MS-I naïve RRMS patients were randomized 2:1 to treatment with i.v. alemtuzumab $12 \mathrm{mg}$ (on days $1-5$ at baseline and on days $1-3$ in a second course 12 months later) or s.c. IFNb-1a 44 mcg tiw.
In CARE-MS II, RRMS considered not responder to DMD were randomized $2: 2: 1$ to alemtuzumab 12 or $24 \mathrm{mg}$ (on days $1-5$ at baseline and on days 1-3 in a second course 12 months later) or IFNb-1a 44 mcg tiw. Alemtuzumab $12 \mathrm{mg} /$ day was more effective than IFNb-1a in the reduction of relapse rate (co-primary endpoint) in patients with treatment-naive $(54.9 \%)$ or previously treated $(49.4 \%)$ RRMS $(p<0.0001$ in both studies). Alemtuzumab $12 \mathrm{mg} /$ day was also significantly $(p<0.0001)$ more effective than IFNb-1a with regard to time to first relapse in both treatment-naive (HR 0.45 [95\% CI 0.33-0.61]) and previously treated patients (HR 0.53 [95\% CI 0.41-0.69]).

The number of patients who were relapse-free at 2 years was significantly $(p<0.0001)$ higher in the alemtuzumab $12 \mathrm{mg} /$ day group than in the IFN-1a group in both studies.. Similarly, alemtuzumab $12 \mathrm{mg} /$ day was more effective than IFNb-1a in the reduction of 6-month confirmed sustained accumulation of disability rate (coprimary endpoint) in patients previously treated RRMS, but there was no significant between-group difference in patients with treatmentnaive RRMS. Alemtuzumab was associated with a risk reduction of $30 \%$ (not significant) in treatment-naive and $42 \%(p=0.0084)$ in previously treated patients for this endpoint. In previously treated patients (CAREMS-II), significantly $(p=0.0002)$ more alemtuzumab $12 \mathrm{mg} /$ day than interferon beta-1a recipients had a sustained reduction in disability score from baseline, confirmed over 6 months, in patients with baseline EDSS scores of >2.0) [HR 2.57 (95\% CI 1.57-4.20)]. Between-group differences in the change in EDSS score were significant $(p<0.0001)$ in previously treated patients, but not in treatment-naive patients.

Alemtuzumab $12 \mathrm{mg} /$ day was significantly $(p<0.05)$ more effective than IFNb-1a with regard to the proportion of patients with Gadolinium-enhancing lesions at 24 months or new or enlarging T2 lesions, and the median change in brain parenchymal fraction in patients with treatment-naïve or previously treated RRMS. No significant between-group difference was observed in the median change in volume of hyperintense lesions in either study. Significantly more recipients of IFNb-1a had new T1 hypointense lesions than recipients of alemtuzumab in previously treated patients; the difference was not significant in treatmentnaive patients. Alemtuzumab was associated with a significantly $(p<0.01)$ greater proportion of patients who were clinically disease free (absence of both relapses and sustained accumulation of disability) and those who were both clinically disease free and MRI disease free (absence of both Gadolinium- enhancing lesions and new or enlarging T2 lesions) than IFNb$1 \mathrm{a}$ in both treatment-naive and previously treated 
patients with RRMS. In a sub-analysis of patients with highly-active RRMS in CARE-MS II (101 alemtuzumab and 42 IFNb-1a recipients), 33.3 and $0 \%$, respectively, were disease activity-free at 1 year $(p<0.0001)$ and $24.2 \%$ of the alemtuzumab recipients remained disease activityfree at 24 months. At 24 months, 35.8 and $60.0 \%$, respectively, had relapses, 7.4 and $17.5 \%$ had sustained accumulation of disability, 22.1 and $52.5 \%$ had gadolinium-enhancing lesion activity, and 60.0 and $92.5 \%$ had T2 -lesion activity.

Supportive analyses demonstrated that significantly fewer alemtuzumab $12 \mathrm{mg} /$ day than interferon beta-1a recipients had severe relapses (reduction of 61 and 48\%; both $p<0.05)$ or relapses leading to steroid treatment (reduction of 58 and $56 \%$; both $p<0.0001$ ) in both treatment-naive and previously treated patients, respectively, and relapses that led to hospitalization in previously treated patients (reduction of 55\%; $p=0.0045$ ).

Data of the five-years extension study of Phase III Clinical Trials have been recently presented at ECTRIMS 2015 [1, 14, 16, 25, 33, 39] The proportion of patients having no evidence of 6-months confirmed disability progression remained high through year $5: 80 \%$ in CARE-MS-I and 76\% in CARE-MS-II compared to respectively 92 and $87 \%$ observed at the end of the trials ( 2 years). More than $50 \%$ of the patients of both studies maintained the NEDA (non evidence of disease activity) at the end of the follow-up. Interestingly, alemtuzumab continued to slow-down the loss of brain volume over the five years: the mean annual rate of brain volume loss ranged between 0.07\% (CARE-MS-II) and 0.2\% (CAREMS-I), a rate similar to that observed in normal individuals $(0.1-0.3 \%)$. Furthermore, the proportion of patients with sustained improvement in pre-existing disability (defined as $\geq 1$-point EDSS decrease over 6 month for patients with EDSS $\geq 2.0$ at core study baseline) increased progressively through 5 years, and was respectively $33 \%$ in CARE-MS-I and $43 \%$ in CARE-MS-II. Finally, the cytokine-release syndrome became progressively milder with repeated administration and the rate of antibody-mediated autoimmunity (thyroid) decreased from $20 \%$ to $10 \%$ from year 3 to year 5 .

Recently, data of 10-year follow-up of patients enrolled in the CAMMS-223 study have been presented at the American Academy Neurology annual congress [15]. Of the 60 patients who enrolled in the long-term follow-up, 20 (33\%) received only the initial 2 courses over 10 years. Of the $39(65 \%)$ patients receiving $>2$ alemtuzumab courses, $26(67 \%)$ only received 3 courses, 7 (12\%) received 4 courses, and $6(10 \%)$ received a total of 5 courses.

Through 10 years of follow-up, a low ARR (0.08) was maintained, while the mean EDSS score change from baseline (SD) was +0.12 over 10 years. Interestingly, EDSS remained stable or improved over 10 years in the majority of patients, and most patients (76\%) showed no evidence of 6-month confirmed disability worsening. These observations indicate that alemtuzumab may provide a unique treatment approach with durable efficacy in the absence of continuous treatment for RRMS patients through 10 years.

\section{Safety profile of alemtuzumab}

The adverse events (AE) complained by up to $90 \%$ of patients during or within $24 \mathrm{~h}$ after alemtuzumab infusion constitute the so-called 'cytokine release syndrome', and appear more frequently on the first day of infusion. The majority of these AE are mild to moderate in severity and are managed by premedication with steroids, anti-pyretics, and anti-histamines. The proportion of patients with $\mathrm{AE}$ is higher during the first course of alemtuzumab than the second.

In the RCT CAMMS223, CARE-MS-I and CARE-MSII, infections were slightly more common with alemtuzumab than with sc IFNb-1a, but most were mild or moderate in severity. Serious infections were reported rarely ( $2-4 \%$ alemtuzumab versus $1 \%$ IFNb-1a). The most common infections were those of the respiratory and urinary tracts. Herpetic infections occurred in $16 \%$ of patients in the CARE-MS I and CARE-MS II studies. The risk of herpetic infection was greatest in the first month posttreatment, and could be reduced by prophylactic oral aciclovir (only $0.5 \%$ of patients receiving aciclovir developed a herpetic infection after the first course of alemtuzumab). Despite the marked immune-depression, no case of progressive multifocal leukoencephalopathy has been reported in alemtuzumab-treated MS patients up to date.

No statistically difference in the risk of cancers was observed after alemtuzumab compared to IFNb-1a in any of the trials (that, however, were not powered to pick up differences in low-frequency events).

Autoimmune AE constitute the most relevant risk of alemtuzumab therapy and have been associated with the characteristic time-course lymphocyte repopulation above described. Three major types of autoimmune disorders have been reported: thyroid diseases in about $30 \%$ of patients (Graves' hyperthyroidism, $65.8 \%$, hypothyroidism, $20.5 \%$, and subacute thyroiditis (12.3\%), idiopatic throbocytopenic purpura (ITP) in $1 \%$ and nephropathy due to anti-glomerular basement membrane antibodies in $0.3 \%$ [8, 12]. In addition, single case of autoimmune neutropenia, pancytopenia and haemolytic anaemia, have been reported in less than $0.5 \%$ of treated patients.

The monitoring schedule recommended in the Lemtrada's Summary of Product Characteristics should be rigorously applied to identify rapidly the first symptoms of autoimmune disease so as to institute appropriate therapy. 
Table 2 Alemtuzumab meets almost all the criteria that are expected from the ideal disease-modifying immunosuppressive/ immunomodulatory drug for multiple sclerosis

\begin{tabular}{ll}
\hline Criteria of the ideal immunosuppressive & YES Partially NO \\
drug & $X$ \\
\hline Rapid biological action & $X$ \\
Rapid clinical effects & $\times$ \\
Long-lasting effects & $X$ \\
Low frequency of injections/ & $\times$ \\
administrations & \\
Respect the patient's quality of life & $\times$ \\
Acceptable costs & $\times$ \\
No non-specific toxicity & $\times$ \\
Low risk of opportunistic infections & \\
No increase risk in cancer & \\
No increase in antibody-mediated & \\
autoimmunity & $\times$ \\
No increase in severe antibody-mediated & $\times$ \\
autoimmunity & $\times$ \\
No increase in mortality & $\times$ \\
Manageable cytokine-release syndrome & \\
Immune system re-modelling/re-shaping &
\end{tabular}

Reviews with more detailed information on safety profile of alemtuzumab are available in the literature (Havrdova et al., 2015; [24, 26, 35]).

\section{Conclusions}

Alemtuzumab can be considered an immunosuppressive drug having complex, yet unexplored, immunomodulatory activities (Table 2). Its biological and clinical actions are fast and, in a large proportion of patients, longlasting. This allows a low frequency of administration, thus making acceptable the infusion-related side effects (the cytokine release syndrome) and the costs of the therapy. In front of an increased in antibody-related autoimmune disorders (mainly autoimmune thyroiditis), it has to be pointed out that the risk of severe, lifethreatening adverse events is extremely low and actually manageable. Moreover, Alemtuzumab seems not to expose the patients to an increased risk of cancer, nospecific toxicity and mortality, and the risk of infectious diseases appears very low. All these features make alemtuzumab a significant step forward in the therapy of MS.

\section{Acknowledgements}

NA.

Funding

NA since the paper is a review.

Availability of data and materials

NA since the paper is a review.

\section{Authors' contributions}

All authors have equally contributed to the manuscript.

Competing interests

All authors have no competing interest.

Consent for publication

NA since the manuscript does not contain individual person's data.

Ethics approval and consent to participate

NA since the paper is a review.

\section{Publisher's Note}

Springer Nature remains neutral with regard to jurisdictional claims in published maps and institutional affiliations.

\section{Author details}

${ }^{1}$ Department of Neuroscience DNS, Multiple Sclerosis Centre, University Hospital, Via Giustiniani, 5, 35129 Padova, Italy. ${ }^{2}$ Neurology and Neuroriabilitation Unit, IRCCS Neuromed, Pozzilli, and Univerity of Tor Vergata, Rome, Italy. ${ }^{3}$ Multiple Sclerosis Centre, Ospedale Binaghi, University of Cagliari, Cagliari, Italy.

Received: 30 January 2017 Accepted: 10 April 2017

Published online: 29 May 2017

References

1. Arnold DL, Traboulsee A, Coles AJ, Cohen JA, Fox EJ, Hartung H, Havrdova E, Selmaj KW, Margolin DH, Zhao Y, et al. Durable effect of alemtuzumab on $\mathrm{MRI}$ activity in treatment-naive active relapsing-remitting multiple sclerosis patients: 4-year follow-up of CARE-MS I. In: Proceedings of the AAN meeting, Washington, DC, USA. 2015.

2. Bandala-Sanchez E, Zhang Y, Reinwald S, Dromey JA, Lee BH, Qian J, Bohmer RM, Harrison LC. T cell regulation mediated by interaction of soluble CD52 with the inhibitory receptor Siglec-10. Nat Immunol. 2013;14:741-8.

3. Ban-Hock T, Tin K, Peter T, Alex B. Immune regulation by CD52-expressing CD4 T cells. Cell Mole Immunol. 2013:10:379-82.

4. Breslin S. Cytokine-release syndrome: overview and nursing implications. Clin J Oncol Nurs. 2007;11(1 Suppl):37-42.

5. Bugelski PJ, Achuthanandam R, Capocasale RJ, Treacy G, Bouman-Thio E. Monoclonal antibody-induced cytokine-release syndrome. Expert Rev Clin Immunol. 2009:5(5):499-521.

6. Buggins AG, Mufti GJ, Salisbury J, et al. Peripheral blood but not tissue dendritic cells express CD52 and are depleted by treatment with alemtuzumab. Blood. 2002;100:1715-20.

7. Clark RA, Watanabe R, Teague JE, Schlapbach C, Tawa MC, Adams N, Dorosario AA, Chaney KS, Cutler CS, Leboeuf NR, Carter JB, Fisher DC, Kupper TS. Skin effector memory T cells do not recirculate and provide immune protection in alemtuzumab-treated CTCL patients. Sci Transl Med. 2012:4(117):117ra7. doi: 10.1126.

8. Cohen JA, Coles AJ, Arnold DL, Confavreux C, Fox EJ, Hartung HP, Havrdova E, Selmaj KW, Weiner HL, Fisher $\mathrm{E}$, et al. Alemtuzumab versus interferon $\beta$ 1a as first-line treatment for patients with relapsing-remitting multiple sclerosis: a randomised controlled phase 3 trial. CARE-MS I. Lancet. 2012;380:1819-28.

9. Coles AJ, Compston DA, Selmaj KW, Lake SL, Moran S, Margolin DH, Norris $\mathrm{K}$, Tandon PK. Alemtuzumab vs. Interferon $\beta-1 \mathrm{a}$ in early multiple sclerosis. N Engl J Med. 2008;359:1786-801.

10. Coles AJ, Fox E, Vladic A, Gazda SK, Brinar V, Selmaj KW, Bass AD, Wynn DR, Margolin DH, Lake SL, et al. Alemtuzumab versus interferon $\beta$-1a in early relapsing-remitting multiple sclerosis: Post-hoc and subset analyses of clinical efficacy outcomes. Lancet Neurol. 2011;10:338-48.

11. Coles A.J, Fox E, Vladic A, Gazda S.K, Brinar V, Selmaj K.W, Skoromets A, Stolyarov I, Bass A, Sullivan $\mathrm{H}$, et al. Alemtuzumab more effective than interferon $\beta$-1a at 5-year follow-up of CAMMS223 clinical trial. Neurology. 2012a;78:1069-1078

12. Coles A.J, Twyman C.L, Arnold D.L, Cohen J.A, Confavreux C, Fox E.J, Hartung, H.P, Havrdova E, Selmaj K.W, Weiner H.L, et al. Alemtuzumab for patients with relapsing multiple sclerosis after disease-modifying therapy: A randomised controlled phase 3 trial. CARE-MS II. Lancet 2012b, 380, 1829-1839

13. Coles AJ. Alemtuzumab treatment of multiple sclerosis. Semin Neurol. 2013; 33(1):66-73. 
14. Coles AJ, Arnold DL, Cohen JA, Fox EJ, Hartung H, Havrdova E, Selmaj KW, Margolin DH, Kasten L, Panzara M, et al. Alemtuzumab slows brain volume loss over 4 years despite most relapsing-remitting multiple sclerosis patients not receiving treatment for 3 years. In: Proceedings of the AAN meeting, Washington, DC, USA. 2015.

15. Coles AJ, Habek M, Bass AN, Brinar V, Vladic A, Margolin DH, Fox EJ, on behalf of the CAMMS223 Investigators. Durable efficacy of alemtuzumab over 10 years: long-term follow-up of patients With RRMS from the CAMMS223 study. In: Poster P3.053, 68th American academy of neurology (AAN) annual meeting, Vancouver, BC, Canada. 2016.

16. Compston DAS, Giovannoni G, Arnold DL, Fox EJ, Hartung H, Havrdova E, Selmaj KW, Margolin DH, Palmer J, Panzara M, et al. Durable effect of alemtuzumab on clinical outcomes in treatment-naive relapsing-remitting multiple sclerosis patients: 4-year follow-up of CARE-MS I. In: Proceedings of the AAN meeting, Philadelphia, PA, USA. 2015

17. Cossburn M, Pace AA, Jones J, Ali R, Ingram G, Baker K, Hirst C, Zajicek J, Scolding N, Boggild M, Pickersgill T, Ben-Shlomo Y, Coles A, Robertson NP. Autoimmune disease after alemtuzumab treatment for multiple sclerosis in a multicenter cohort. Neurology. 2011;77(6):573-9.

18. Costelloe $L$, Jones J, Coles A. Secondary autoimmune diseases following alemtuzumab therapy for multiple sclerosis. Expert Rev Neurother. 2012; 12(3):335-41.

19. Cox AL, Thompson SA, Jones JL, Robertson VH, Hale G, Waldmann H, Compston DA, Coles AJ. Lymphocyte homeostasis following therapeutic lymphocyte depletion in multiple sclerosis. Eur J Immunol. 2005;35:3332-42.

20. De Mercanti S, Rolla S, Cucci A, Bardina V, Cocco E, et al. Alemtuzumab longterm immunologic effect. Neurol Neuroimmunol Neuroinflamm. 2016;3:e194.

21. Genzyme Therapeutics Ltd. LemtradaTM (alemtuzumab 12 mg concentrate for solution for infusion): EU summary of productcharacteristics. 2013. http:// www.ema.europa.eu/docs/en_GB/document_library/EPAR_-_Product_ Information/human/003718/WC500150521.pdf. Accessed 16 Oct 2013.

22. Hale G, Bright S, Chumbley G, Hoang T, Metcalf D, Munro AJ, Waldmann H. Removal of T cells from bone marrow for transplantation: a monoclonal antilymphocyte antibody that fixes human complement. Blood. 1983;62:873-82.

23. Hale G, Waldmann $\mathrm{H}$. From laboratory to clinic : the story of CAMPATH-1. Methods Mol Med. 2000;40:243-66.

24. Hartung H-P, Aktas O, Boyko AN. Alemtuzumab: a new therapy for active relapsing-remitting multiple sclerosis. Mult Scler. 2015;21(1):22-34.

25. Havari E, Turner M, Dodge J, Treleaven C, Shihabuddin L, et al. Antimurine CD52 antibody treatment does not adversely affect the migratory ability of immune cells. In: Proceedings of the AAN Meeting, Philadelphia, PA, USA. 2015.

26. Havrdova E, Horakova D, Kovarova I. Alemtuzumab in the treatment of multiple sclerosis: key clinical trial results and considerations for use. Ther Adv Neurol Disord. 2015;8(1):31-45.

27. Helliwell CL, Coles AJ. Monoclonal antibodies in multiple sclerosis treatment: current and future steps. Ther Adv Neurol Disord. 2009;2(4):195-203.

28. Hill-Cawthorne GA, Button T, Tuohy O, Jones JL, May K, Somerfield J, Green A, Giovannoni G, Compston DA, Fahey MT, Coles AJ. Long term lymphocyte reconstitution after alemtuzumab treatment of multiple sclerosis. J Neurol Neurosurg Psychiatry. 2012;83(3):298-304.

29. Hu Y, Turner MJ, Shields J, Gale MS, Hutto E, et al. Investigation of the mechanism of action of alemtuzumab in a human CD52 transgenic mouse model. Immunology. 2009;128:260-70.

30. Jones JL, Phuah CL, Cox AL, Thompson SA, Ban M, Shawcross J, Walton A, Sawcer SJ, Compston A, Coles AJ. IL-21 drives secondary autoimmunity in patients with multiple sclerosis, following therapeutic lymphocyte depletion with alemtuzumab (Campath-1H). J Clin Invest. 2009;119(7):2052-61.

31. Jones JL, Anderson JM, Phuah CL, Fox EJ, Selmaj K, Margolin D, Lake SL, Palmer J, Thompson SJ, Wilkins A, et al. Improvement in disability after alemtuzumab treatment of multiple sclerosis is associated with neuroprotective autoimmunity. Brain. 2010;133:2232-47.

32. Jones JL, Thompson SA, Loh P, et al. Human autoimmunity after lymphocyte depletion is causedby homeostatic T-cell proliferation. Proc Natl Acad Sci U S A. 2013;110:20200-5.

33. LaGanke C, Hughes B, Berkovich R, Cohen JA, Giovannoni G, Kasten L, Margolin DH, Havrdova E. Durable effect of alemtuzumab on disability improvement in patients with relapsing-remitting multiple sclerosis who relapsed on a prior therapy. In: Proceedings of the AAN meeting, Washington, DC, USA. 2015.
34. McCarthy CL, Tuohy O, Compston DA, Kumararatne DS, Coles AJ, Jones JL. Immune competence after alemtuzumab treatment of multiple sclerosis. Neurology. 2013;81(10):872-6.

35. Menge T, Stuve O, Kieseier BC, Hartung H-P. Alemtuzumab. The advantages and challenges ofa novel therapy in MS. Neurology. 2014;83:87-97.

36. Rao SP, Campos-Rivera J, Sancho J, et al. Differential sensitivity of human PBMC subsets to alemtuzumab mediated cytotoxicity. Mult Scler. 2010;16: S139-40.

37. Rao SP, Sancho J, Campos-Rivera J, Boutin PM, Severy PB, et al. Human peripheral blood mononuclear cells exhibit heterogeneous CD52 expression levels and show differential sensitivity to alemtuzumab mediated cytolysis. PLoS One. 2012;7:e39416.

38. Thompson SA, Jones JL, Cox AL, Compston DA, Coles AJ. B-cell reconstitution and BAFF after alemtuzumab (Campath-1H) treatment of multiple sclerosis. J Clin Immunol 2010;30(1):99-105.

39. Traboulsee A, Coles AJ, Cohen JA, Compston DAS, Fox EJ, Hartung H, Havrdova E, Selmaj KW, Margolin DH, Zhao Y, et al. Durable effect of alemtuzumab on MRI outcomes in patients with relapsing-remitting multiple sclerosis who relapsed on prior therapy: 4-year follow-up of CAREMS II. In: Proceedings of the AAN meeting, Washington, DC, USA. 2015.

40. Turner MJ, Lamorte MJ, Chretien N, Havari E, Roberts BL, et al. Immune status following alemtuzumab treatment in human CD52 transgenic mice. J Neuroimmunol. 2013;261:29-36.

41. Turner MJ, Pang PT, Chretien N, Havari E, LaMorte MJ, et al. Reduction of inflammation and preservation of neurological function by anti-CD52 therapy in murine experimental autoimmune encephalomyelitis. J Neuroimmunol. 2015;285:4-12.

42. Zhang X, Tao Y, Chopra M, Ahn M, Marcus KL, et al. Differential reconstitution of $T$ cell subsets following immunodepleting treatment with alemtuzumab (anti-CD52 monoclonal antibody) in patients with relapsingremitting multiple sclerosis. J Immunol. 2013;191:5867-74.

43. Wang $H$, Dong J, Shi $P$, et al. Anti-mouse CD52 monoclonal antibody ameliorates intestinal epithelial barrier functionin interleukin-10 knockout mice with spontaneous chronic colitis. Immunology 2015;144(2):254-262.

44. Watanabe T, Masuyama J, Sohma Y, Inazawa H, Horie K, et al. CD52 is a novel costimulatory molecule for induction of CD4+ regulatory $T$ cells. Clin Immunol. 2006;120(3):247-59.

45. Wing MG, Moreau T, Greenwood J, Smith RM, Hale G, et al. Mechanism of first-dose cytokine-release syndrome by CAMPATH 1-H: involvement of CD16 (FcgammaRIII) and CD11a/CD18 (LFA-1) on NK cells. J Clin Invest. 1996;98(12):2819-26.

\section{Submit your next manuscript to BioMed Central and we will help you at every step:}

- We accept pre-submission inquiries

- Our selector tool helps you to find the most relevant journal

- We provide round the clock customer support

- Convenient online submission

- Thorough peer review

- Inclusion in PubMed and all major indexing services

- Maximum visibility for your research

Submit your manuscript at www.biomedcentral.com/submit 